\title{
CARACTERIZAÇÃO DE FRUTOS DE DIFERENTES ESPÉCIES DE MARACUJAZEIRO
}

Laísse Danielle Pereira ${ }^{1}$, Karminne Dias do Valle ${ }^{2}$, Lásara Kamila Ferreira de Souza ${ }^{3}$, Hildeu Ferreira da Assunção ${ }^{4}$, Cecília de Castro Bolina ${ }^{4}$, Edésio Fialho dos Reis ${ }^{4}$, Alejandro Hurtado Salazar ${ }^{5}$, Danielle Fabíola Pereira da Silva ${ }^{4}$

\begin{abstract}
RESUMO - O maracujá é um fruto tropical que tem grande aceitabilidade e o seu cultivo possibilita diversificação dos cultivos e contribui para geração de renda. Objetivou-se com este trabalho avaliar as características físicas de frutos de três espécies de maracujazeiro produzidas no sudoeste de Goiás. Os frutos utilizados no experimento foram provenientes da Estação Experimental Universidade Federal de Goiás - Regional Jataí. Frutos com maturação fisiológica completa foram colhidos sendo utilizado como critério a mudança da coloração da epiderme da cor verde para a cor amarela. Posteriormente foram encaminhados ao laboratório e avaliados quanto à massa fresca, massa da epiderme e massa da polpa, comprimento, diâmetro, relação entre o comprimento e o diâmetro, espessura da epiderme, atributos de cor da epiderme e polpa, teor de sólidos solúveis e rendimento de suco. O delineamento experimental foi em blocos casualizados, com três tratamentos correspondendo aos genótipos Passiflora edulis flavicarpa (cultivar comercial FB 200), Passiflora edulis flavicarpa (maracujazeiro-azedo) e Passiflora alata (maracujazeiro-doce), com quatro repetições, sendo dez frutos por parcela experimental. Os dados foram submetidos à análise de variância e teste de Tukey, em nível de $5 \%$ de probabilidade. Frutos da cultivar FB200 apresentaram maior diâmetro e maior rendimento de suco. Frutos de Maracujazeiro-doce obtiveram menor tamanho e, consequentemente, menor rendimento de suco. Frutos de maracujazeiro-azedo obtiveram maior tamanho e não diferiu de frutos do Maracujazeiro-doce quanto ao no rendimento de suco.
\end{abstract}

Palavras chave: Passiflora alata, Passiflora edulis f. edulis Sims, qualidade.

\section{CHARACTERIZATION OF FRUITS OF DIFFERENT SPECIES OF PASSION FRUIT}

\begin{abstract}
Passion fruit is a tropical fruit that has great acceptability and its cultivation makes it possible to diversify crops and contribute to income generation. The objective of this work was to evaluate the physical characteristics of fruits of three species of passion fruit produced in southwest of Goiás. The fruits used in the experiment were from the Federal University of Goiás - Regional Jataí Experimental Station. Fruits with complete physiological maturation were harvested, being used as criterion the change of the coloration of the epidermis of the green color to the yellow color. Afterwards they were sent to the laboratory and evaluated for fresh mass, epidermal mass and pulp mass, length, diameter, length-to-diameter ratio, epidermal thickness, epidermal and pulp color attributes, soluble solids content and yield of juice. The experimental design was in a randomized block design, with three treatments corresponding to the genotypes Passiflora edulis flavicarpa (commercial cultivar FB 200), Passiflora edulis flavicarpa (yellow passion fruit) and Passiflora alata (sweet passion fruit), with four replications, ten fruits per plot experimental. Data were submitted to analysis of
\end{abstract}

\footnotetext{
${ }^{1}$ Engenheira Agrônoma - Mestranda do Programa de Pós-graduação em Agronomia (Bolsista da CAPES) - laissedaniellep@gmail.com

${ }^{2}$ Discente do Curso de Agronomia/ Bolsista de Iniciação Científica do CNPq - Universidade Federal de Goiás, Regional Jataí - karminnevalle@gmail.com

${ }^{3}$ Engenheira Florestal - Mestranda do Programa de Pós-graduação em Agronomia (Bolsista da CAPES) - engekah.lk@gmail.com

${ }^{4}$ Engenheiros Agrônomos - Professores - Universidade Federal de Goiás - UFG/Jataí, Goiás -Brasil. hildeu@yahoo.com.br, ceciliabolina@bol.com.br, edesiofr7@gmail.com,daniellefpsilva@gmail.com

${ }^{5}$ Engenheiro Agrônomo - Professor - Universidad de Caldas, Manizales, Colombia, alhuza@gmail.com
} 
variance and Tukey's test, at a 5\% probability level. Fruits of the cultivar FB200 presented larger diameter and higher yield of juice. Fruits of Sweet passion fruit obtained smaller size, and consequently lower yield of juice. Fruits of yellow passion fruit obtained larger size and did not differ from sweet passion fruit fruits as compared to juice yield.

Keywords: Passiflora alata, Passiflora edulis f. edulis Sims, quality.

\section{INTRODUÇÃO}

O maracujazeiro é uma fruteira de clima tropical que tem grande aceitabilidade tanto para consumo in natura, quanto para a industrialização, sendo o Brasil o maior produtor e o maior consumidor mundial. Em 2016, a produção brasileira foi de 703.489 toneladas em uma área de 49.889 hectares (IBGE, 2017). A Região Centro-Oeste situa-se atualmente em quinto lugar entre as regiões produtoras de maracujá (Instituto FNP, 2017). O estado de Goiás, por sua vez, produziu 6.099 toneladas em uma área de 375 hectares; todavia, são inexistentes dados de cultivo no sudoeste goiano, sendo essa produção distribuída em outras regiões do estado.

O Brasil é o centro de origem de aproximadamente um quarto de espécies do gênero Passiflora e por isso possui potencial de exploração de espécies silvestres e desenvolvimento de outras cultivares comercias (Cerqueira-Silva et al., 2014), como a cultivar FB200.

Assim como a espécie Passiflora edulis Sims. f. flavicarpa, a espécie Passiflora alata tem despertado grande interesse do mercado nacional e internacional e, segundo Maciel et al. (2009), no cultivo de Passiflora no Brasil, essa espécie corresponde a $3 \%$ da área destinada a cultura.

Frutos de maracujá que são destinados ao mercado in natura, onde o parâmetro utilizado para avaliação da qualidade é a aparência externa, sendo este um dos problemas identificados pela cadeia produtiva para a comercialização, devido à perda de massa que leva ao murchamento, dando ao fruto aspecto enrugado (Rinaldi et al., 2017).

$\mathrm{O}$ fruto de boa qualidade e que desperta o interesse do consumidor final é aquele que apresenta características físicas favoráveis, tais como cor da epiderme, tamanho, firmeza da polpa, bom estado fitossanitário e sabor (Giovanaz et al., 2014 \& Silva-Filho et al., 2015).

Atualmente o sudoeste goiano se destaca como grande produtor de grãos, como soja e milho (IBGE, 2017). Entretanto, este apresenta condições favoráveis ao desenvolvimento da espécie, oferecendo solo, clima, topografia e disponibilidade de água para a expansão da cultura. Desta forma, o objetivo deste trabalho foi avaliar as características físicas de frutos de três espécies de maracujazeiro produzidas no sudoeste de Goiás.

\section{MATERIAL E MÉTODOS}

Os frutos utilizados no desenvolvimento do experimento foram provenientes do Pomar Experimental da Universidade Federal de Goiás - Regional Jataí, nas coordenadas $17^{\circ} 53^{\prime} 08^{\prime \prime} \mathrm{S}$ e $51^{\circ} 40^{\prime} 12^{\prime \prime} \mathrm{O}$, com altitude média de $789 \mathrm{~m}$. Segundo a classificação de Köppen, o clima da região é do tipo Aw, megatérmico, com a estação seca definida de maio a setembro, e a chuvosa, de outubro a abril. A temperatura média é $23,3^{\circ} \mathrm{C}$ e a média anual de pluviosidade é de $1541 \mathrm{~mm}$.

Frutos com maturação fisiológica completa foram colhidos de forma manual, com auxílio de tesoura de poda, sendo utilizado como critério de colheita a mudança da coloração da epiderme da cor verde para a cor amarela.

Após a colheita, foram acondicionados em caixas plásticas, colocando-se apenas uma camada de fruto, evitando danos causados por atrito. Posteriormente foram encaminhados ao laboratório, lavados em água corrente e secos ao ar e em seguida avaliados quanto a características físicas e químicas.

Os frutos foram avaliados quanto a massa fresca (MF), massa da epiderme (ME) e massa da polpa (MP). Os dados foram obtidos com o auxílio de balança de precisão e os resultados expressos em gramas (g). O comprimento do fruto (CF), diâmetro do fruto (DF) e espessura da epiderme (EE) foram avaliados com auxílio de paquímetro digital, cujos dados foram determinados em milímetros. A relação entre o comprimento e o diâmetro (CF/DF) foi obtida pela razão CF e DF.

A cor da epiderme (medida na região equatorial de uma das faces do fruto) e da polpa foi dada pela coordenada $\mathrm{C}^{*}$ e ângulo Hue $\left(\mathrm{h}^{\circ}\right)$, utilizando colorímetro Konica Minolta, modelo CR-10, que mede a luz refletida, 
usando-se um sistema de coordenadas cartesianas $\mathrm{L}^{*}$, $a^{*}$ e b*, das quais se obtêm unidades ou pontos de uniformidade visual aproximada. $\mathrm{O}$ valor $\mathrm{a}^{*}$ corresponde à escala vermelho-verde e varia de +60 a -60 , correspondendo os valores negativos às distintas tonalidades de cor verde e os positivos, às tonalidades vermelhas. O parâmetro $b^{*}$ corresponde à escala amareloazul e varia igualmente de +60 a -60 , ressaltando-se que os valores negativos correspondem às tonalidades de cor azul e os positivos, às tonalidades de cor amarela. O L* refere-se ao nível de luminosidade, variando de 0 (para cor preta) a 100 (para cor branca). O teor de sólidos solúveis (SS), expresso em ${ }^{0} \mathrm{Brix}$, foi mensurado utilizando-se refratômetro portátil. O rendimento de suco (\%), foi calculado pela relação entre o peso de suco/peso do fruto.

O delineamento experimental foi em blocos casualizados, com três tratamentos correspondendo frutos de Passiflora edulis flavicarpa (cultivar comercial FB 200), frutos de Passiflora edulis flavicarpa (maracujazeiro-azedo) e frutos de Passiflora alata (maracujazeiro-doce), com quatro repetições, sendo dez frutos por cada repetição, totalizando 40 frutos avaliados por tratamento.

Os dados foram submetidos à análise de variância e comparação de médias pelo teste de Tukey, em nível de $5 \%$ de probabilidade. Os cálculos referentes às análises estatísticas foram executados, utilizandose do software estatístico SAS (Statistical Analysis System, 2002).

\section{RESULTADOS E DISCUSSÃO}

Houve variação média entre massa fresca dos frutos avaliados, sendo atribuída massa fresca média de $270 \mathrm{~g}$ para o maracujazeiro-azedo, $170 \mathrm{~g}$ para o maracujazeiro-doce e de 310 g para FB200 (Tabela 1). Não foram observadas diferenças estatísticas significativas entre as cultivares FB200 e azedo para a variável avaliada.

A diferença observada entre as médias da massa fresca dos frutos evidencia que o acúmulo de massa está relacionado ao aumento no volume e nas dimensões dos frutos, sendo estes eventos regulados fortemente por hormônios durante o crescimento e a maturação dos frutos (McAtee et al., 2013), demostrando que frutos provenientes da cultivar FB200 são maiores e consequentemente apresentam maior peso.
A comercialização do maracujazeiro é realizada por peso da massa fresca do fruto e aparência. Por esse motivo, o conhecimento do peso dos frutos de cada espécie e ou cultivar é de fundamental importância (Rotili et al., 2013).

Avaliando produtividade e qualidade de frutos de cultivares de maracujazeiro amarelo com e sem polinização artificial em Tangará da Serra-MT, para a cultivar FB 200, sem polinização artificial, a massa fresca obtida foi de 175,9 g (Krause et al., 2012). Já Cobra et al. (2015) obtiveram valor médio de massa fresca de 131,8 g na cultivar FB 200, onde os autores trabalharam com cultivares comerciais no Mato Grosso. Estes valores foram inferiores aos aqui encontrados, confirmando assim o potencial produtivo do sudoeste goiano.

Salazar et al. (2015) obtiveram em condições de ambiente protegido para o maracujazeiro-amarelo média de $157,4 \mathrm{~g}$ para massa fresca do fruto, valor inferior aos encontrados no presente trabalho. Alves et al. (2012), trabalhando com maracujazeiro-doce nas condições de Viçosa-MG, encontraram 194,8 g para a massa fresca de fruto, sendo superior a encontrada no presente trabalho para a mesma espécie.

Rinaldi et al. (2017), estudando a conservação póscolheita de frutos de Passiflora setacea DC, encontraram valores médios para a massa do fruto, próximos a 51,30 $\mathrm{g}$, sendo bem inferiores aos resultados encontrados no presente trabalho. Ataíde et al. (2012), em frutos de Passiflora setacea produzidos em Jaboticabal SP, obtiveram resultados inferiores aos encontrados em todas as cultivares avaliadas no presente estudo, ressaltando que diante dos resultados expostos as condições edafoclimáticas da região, são propícias para o cultivo da espécie.

O efeito da combinação entre respiração e transpiração faz com produtos perecíveis, mesmo quando mantidos em condições ideais de temperatura e umidade, perca massa durante o armazenamento (Chitarra \& Chitarra, 2005).

Segundo a Federação da Agricultura do Estado do Paraná-FAEP (2015), frutos de maracujazeiro-amarelo para serem considerados murchos, a perda de massa fresca deverá ser de até $8 \%$ do seu peso inicial, pois a partir desse ponto, sua aparência é prejudicada e consequentemente existirá uma depreciação no seu valor comercial. Frutos de maior massa são também 
os de maior tamanho, e estes, por sua vez, são mais atrativos para indústria (Santos et al., 2015) e para o mercado in natura, visto que o consumidor tem preferência por frutos grandes (Durigan et al., 2004).

O diâmetro médio dos frutos teve variação entre 66,43 a 91,85 mm (Tabela 1). Essa variação pode ser explicada pelas alterações quantitativas que ocorrem na fase de crescimento do fruto, influenciando no aumento do peso e volume de água nesse órgão. Como também por fatores ligados ao ambiente, como temperatura, radiação solar e precipitação que, segundo Berilli et al. (2007), podem influenciar nessas características, assim como os fatores genéticos intrínsecos de cada material vegetal variando entre espécies e cultivares de um mesmo gênero.

Resultados semelhantes foram encontrados por Krause et al. (2012), que observaram valores médios dos frutos em torno de 70,4 mm, e para a cultivar FB 200 , foi encontrado $76,2 \mathrm{~mm}$. No presente trabalho os frutos com maiores diâmetros foram obtidos pela cultivar FB200 e maracujazeiro-azedo, com 91,85 e 89,43 mm, respectivamente, não diferindo estatisticamente entre si. Os frutos do maracujazeiro-doce apresentaram diâmetro médio inferior aos demais, com valores médios de 66, 43 mm. Conforme classificação de Medeiros et al. (2009), em relação ao diâmetro, a cultivar FB200 e maracujazeiroazedo foram classificados como $3 \mathrm{~A}$, ou seja, diâmetro do fruto maior que $85 \mathrm{~mm}$, enquanto que a cultivar maracujazeiro-doce foi classificada como $2 \mathrm{~A}$, ou seja, diâmetro entre 75 e $85 \mathrm{~mm}$.

Botelho et al. (2017) avaliando a qualidade póscolheita de frutos de maracujazeiro-amarelo produzidos no estado do Mato Grosso, observaram que para a cultivar FB200, os maiores valores de diâmetro foram obtidos em Terra Nova do Norte $(87,66 \mathrm{~mm})$ e Cáceres $(85,19 \mathrm{~mm})$ valores semelhantes aos encontrados para o maracujazeiro-azedo e discrepante aos encontrados para a cultivar FB 200.

Cobra et al. (2015) encontraram diâmetro médio de $82,6 \mathrm{~mm}$ para as cultivares comerciais estudadas. Já Salazar et al. (2015) encontraram 71,49 mm para frutos de maracujazeiro-amarelo. Para os frutos de maracujazeirodoce, Alves et al. (2012) obtiveram diâmetro médio de $74,59 \mathrm{~mm}$, sendo todos os valores inferiores aos do presente estudo. É perceptível a importância dessa característica para a comercialização frutos do maracujazeiro, sendo desejável a presença dela, visto que são classificados comercialmente quanto à medida de seu diâmetro.

O comprimento médio dos frutos variou de 84,4 a $102,6 \mathrm{~mm}$ (Tabela 1). Os frutos com maiores comprimentos foram de FB 200, com 102,6 mm, não diferindo do Maracujazeiro-azedo, com 102,51 mm, sendo que ambos foram superiores aos frutos de maracujazeirodoce, com 84,4 mm. Schmildt et al. (2017), trabalhando com dimensionamento amostral para analisar caracteres físicos e químicos de frutos de maracujá-fedorento, encontraram valores médios para o comprimento do fruto próximos a 19,46 mm, sendo inferiores aos encontrados para todas as cultivares avaliadas.

Krause et al. (2012) em seu trabalho com a cultivar FB 200 encontraram comprimento médio de $86,3 \mathrm{~mm}$, valores discrepantes aos aqui encontrados. Para o maracujazeiro-doce, Alves et al. (2012) encontraram

Tabela 1 - Caracterização física de frutos das plantas de FB 200 (FB), Maracujazeiro-azedo (MA) e Maracujazeirodoce (MD). MFF (massa fresca do fruto); CF (comprimento do fruto); DF (diâmetro do fruto); EE (espessura da epiderme); MP (massa da epiderme); MP (massa da polpa); C: coordenada C; h: coordenada h (ângulo hue); SST (teor de sólidos solúveis) e Rto suco (rendimento de suco). Jataí$\mathrm{GO}, 2016$

\begin{tabular}{|c|c|c|c|c|c|c|c|c|c|c|c|c|c|}
\hline \multirow{2}{*}{ Espécie* } & \multirow{2}{*}{$\operatorname{MFF}(\mathrm{g})$} & \multirow{2}{*}{$\mathrm{CF}(\mathrm{mm})$} & \multirow{2}{*}{$\mathrm{DF}(\mathrm{mm})$} & \multirow{2}{*}{$\mathrm{CF} / \mathrm{DF}$} & \multicolumn{2}{|c|}{ Cor epiderme } & \multirow{2}{*}{$\mathrm{EE}(\mathrm{mm})$} & \multirow{2}{*}{ MC(g) } & \multirow{2}{*}{$\mathrm{MP}(\mathrm{g})$} & \multicolumn{2}{|c|}{ Cor polpa } & \multirow{2}{*}{ SST } & \multirow{2}{*}{ Rto suco(\%) } \\
\hline & & & & & $\mathrm{C}$ & $\mathrm{h}$ & & & & $\mathrm{C}$ & $\mathrm{h}$ & & \\
\hline FB & $310 \mathrm{a}$ & $102,6 \mathrm{a}$ & $91,9 \mathrm{a}$ & $1,1 \mathrm{~b}$ & $37,8 \mathrm{a}$ & $95,1 \mathrm{a}$ & $7,2 \mathrm{c}$ & $170,3 \mathrm{a}$ & $123 \mathrm{a}$ & $25,7 \mathrm{a}$ & $93,6 \mathrm{a}$ & $12,6 \mathrm{~b}$ & $40,6 \mathrm{a}$ \\
\hline MA & $270 \mathrm{a}$ & $102,5 \mathrm{a}$ & 89,4 a & $1,2 \mathrm{~b}$ & $31,8 \mathrm{a}$ & $80,5 \mathrm{~b}$ & $9,1 \mathrm{~b}$ & $154,5 \mathrm{a}$ & $71,4 \mathrm{~b}$ & $26,0 \mathrm{a}$ & $92,4 \mathrm{a}$ & $10,6 \mathrm{c}$ & $31,9 \mathrm{~b}$ \\
\hline $\mathrm{MD}$ & $170 \mathrm{~b}$ & $84,4 \mathrm{~b}$ & $66,4 \mathrm{~b}$ & $1,3 \mathrm{a}$ & $41,8 \mathrm{a}$ & $80,8 \mathrm{~b}$ & $11,1 \mathrm{a}$ & $103,1 \mathrm{~b}$ & $45,9 \mathrm{c}$ & $10,7 \mathrm{~b}$ & $92,6 \mathrm{a}$ & $18,6 \mathrm{a}$ & $32,3 \mathrm{~b}$ \\
\hline CV $(\%)$ & 28,1 & 15,1 & 16,2 & 12,1 & 22,8 & 18,63 & 27,9 & 23,1 & 29,3 & 22,7 & 25,4 & 21,8 & 23,3 \\
\hline
\end{tabular}

*Espécies: FB (cultivar FB 200), MA (maracujazeiro-azedo) e MD (maracujazeiro-doce).

Médias seguidas pela mesma letra na coluna não diferem entre si em nível de $0,05 \%$ de probabilidade. 
$85,35 \mathrm{~mm}$ de comprimento, corroborando com os valores encontrados neste trabalho.

As menores dimensões do fruto, ou seja, menor comprimento médio e menor diâmetro médio foram observados em frutos provenientes da cultivar maracujazeiro-doce, o que explica o menor valor em relação a massa descrita anteriormente para os frutos dessa mesma espécie.

Observou-se para a relação $\mathrm{CF} / \mathrm{DF}$ que frutos de FB200 e maracujazeiro-azedo não diferiram entre si estatisticamente, com 1,12 e 1,25, respectivamente (Tabela 1). Para frutos de Maracujazeiro-doce esta relação foi de 1,27, diferindo estatisticamente dos demais tratamentos. De acordo com Greco et al. (2014), a relação entre o comprimento e o diâmetro (CF/DF) é utilizada para avaliar o formato dos frutos, considerando-se o valor igual a um para fruto redondo e maior, para fruto ovalado. Assim, os frutos das espécies em estudo são classificados como ovalados.

Os maiores frutos foram obtidos em plantas FB 200, não diferindo dos frutos de Maracujazeiro-azedo, e ambos foram superiores aos de maracujazeiro-doce. De acordo com Silva et al. (2016), quanto maior a fruta, maior é seu rendimento em polpa, menores os gastos com mão de obra, e em equipamentos industriais, melhor a aparência e, portanto, maior seu valor comercial.

Para a espessura de epiderme, os valores não apresentaram diferença significativa entre as médias dos frutos (Tabela 1). A espessura de casca é uma característica importante, tanto para a indústria de suco concentrado, quanto para o mercado da fruta in natura, pois existe transferência de água da casca para a polpa do maracujá por ser inversamente proporcional ao rendimento do suco (Vianna-Silva et al., 2010).

O maracujazeiro-doce apresentou maior média $(11,08$ $\mathrm{mm}$ ), seguido do maracujazeiro-azedo com $9,06 \mathrm{~mm}$, e com menor espessura, os frutos da cultivar FB 200 apresentaram média de 7,20 mm. Krause et al. (2012), estudando a produtividade e qualidade de frutos de cultivares de maracujazeiro-amarelo com ou sem polinização artificial, encontraram médias entre 6,4 a 7,4 $\mathrm{mm}$ para a espessura da epiderme, sendo esses valores inferiores aos encontrados para a mesma cultivar no presente estudo.

Alves et al. (2012) encontraram em frutos de Maracujazeiro-doce 9,92 $\mathrm{mm}$ de espessura média da epiderme, valor abaixo do encontrado neste trabalho. É preferível que a epiderme seja mais grossa para frutos de mesa, para evitar danos pós-colheita no transporte (Krause et al., 2012). De acordo com Freire et al. (2014), frutos destinados à indústria precisam ter casca fina e possuir cavidade interna totalmente preenchida, a fim de conferir alto rendimento de suco.

O Teor de Sólidos Solúveis variou de 10,59 a 18,58 ${ }^{\circ}$ Brix. Com a maturação o teor de SS tende a aumentar, seja por biossíntese, pela degradação excessiva de polissacarídeos ou, ainda, pela excessiva perda de água do fruto (Chitarra \& Chitarra, 2005).

Os maiores teores foram encontrados nos frutos da cultivar maracujazeiro-doce, com $18,58^{\circ}$ Brix. Possivelmente essa espécie acumula mais amido que as demais e quando ocorre à hidrólise do amido durante o amadurecimento do fruto, que resulta no incremento do teor de sólidos solúveis, sendo que esta apresenta maiores teores por possuir maiores quantidades de amido, diferindo estatisticamente dos frutos de FB 200 e maracujazeiro-azedo, que apresentaram 12,58 e 10,59 ${ }^{\circ}$ Brix, respectivamente.

Córdova et al. (2008), estudando suco de maracujá orgânico, obtiveram sólidos solúveis totais de $14,23^{\circ}$ Brix, valor semelhante aos encontrados no presente estudo. Krause et al. (2012) encontraram valores médios de teor de sólidos solúveis para a cultivar FB 200 de $13,9^{\circ}$ Brix, sendo superior aos encontrados neste trabalho.

Segundo Cobra et al. (2015), em trabalho com características florais e polinizadores na qualidade de frutos de cultivares de maracujazeiro-azedo, a cultivar FB200 apresentou $12,7^{\circ}$ Brix, valor inferior ao mínimo indicado para o mercado in natura ou indústria, que segundo o mesmo autor é de $13^{\circ} \mathrm{Brix}$. Este valor é semelhante ao encontrado neste trabalho, embora os frutos oriundos de Maracujazeiro-doce avaliados por Alves et al. (2012) tenham apresentado $18,20^{\circ}$ Brix.

Na coloração da epiderme dos frutos, não se observou diferença estatística quanto aos valores do croma, sendo $37,79,31,81$ e 41,84 para FB 200, maracujazeiro-azedo e maracujazeiro-doce, respectivamente, indicando que a saturação ou a quantidade de pigmento na epiderme é alta, e não apresenta variação entre as cultivares.

A diferença na coloração da casca é expressa pelo ângulo hue, o que permite visualizar a mudança na cor dos frutos, de verde para amarela (Azzolini et al., 
2004). O ângulo hue para FB 200 ficou situado dentro do segundo quadrante $\left(>90^{\circ} \mathrm{C}\right)$, ou seja, coloração amarela, com valor de 95,10 , determinando maior intensidade do amarelo, diferindo das demais.

Já o maracujazeiro-azedo e o maracujazeiro-doce apresentaram valores entre $80,54 \mathrm{e} 80,75$, respectivamente, situados dentro do primeiro quadrante (de zero a $90^{\circ}$ ), ou seja, coloração variando do vermelho ao amarelo.

Para cor da polpa, os frutos da FB 200 e maracujazeiroazedo obtiveram croma com valores de 25,72 e 26,01, respectivamente, não diferindo estaticamente entre si. Já os frutos de maracujá-doce apresentaram croma de 10,71 , indicando que a saturação ou quantidade de pigmento presente na polpa é menor que as demais.

O ângulo hue expressa as diferenças na coloração da casca, permitindo visualizar a mudança na cor dos frutos, de verde para amarela (Azzolini et al., 2004). Para este não se observou diferença entre os frutos avaliados, ficando situados no segundo quadrante, com valores entre 93,69 a 92,38, indicando maior predominância da cor amarela.

A cor da epiderme e da polpa são os critérios mais importantes na escolha do fruto, além da ausência de defeitos. Em caso de polpa com amarelo mais claro, o seu uso na indústria pode requerer o aditivo de corantes, o que pode elevar os custos com o processamento (Morais et al., 2017).

$\mathrm{Na}$ porcentagem de rendimento de suco, frutos obtidos da cultivar FB200 apresentaram maior valor de média, com $40,57 \%$, diferentemente dos frutos provenientes das cultivares maracujazeiro-azedo e maracujazeiro-doce, com 31,90 e 32,35\%, que não apresentaram diferença estatística.

Salazar et al. (2015) encontraram valores médios de rendimento de suco de 56,63\% em maracujazeiroamarelo em ambiente protegido. Krause et al. (2012) encontraram $37,9 \%$ para a cultivar FB200. Em frutos de maracujazeiro-doce, Alves et al. (2012) encontraram $23,3 \%$ de polpa, valor abaixo dos encontrados neste trabalho.

Nascimento et al. (1999) afirmaram que o rendimento em suco de frutos que se destinam à industrialização deve ser de, no mínimo, $33 \%$ da massa total do fruto, pois a indústria prefere frutos de alto rendimento em suco e com alto teor de sólidos solúveis totais.

\section{CONCLUSÕES}

Frutos da cultivar FB200 se destacaram com maior diâmetro, maior massa e maior rendimento de suco, sendo esta cultivar indicada para a industrialização.

Frutos de Maracujazeiro-azedo foram inferiores aos de FB200, mas superiores aos de maracujazeirodoce, sendo indicado tanto para a industrialização quanto para consumo in natura.

Frutos de Maracujazeiro-doce obtiveram menor tamanho e, consequentemente, menor rendimento de suco, entretanto apresentaram maior teor de ${ }^{\circ}$ Brix, sendo indicados para consumo in natura.

\section{LITERATURA CITADA}

ALVES, R.R.; SALOMÃO, L.C.C.; SIQUEIRA, D.L. et al. Relações entre características físicas e químicas de frutos de maracujazeiro-doce cultivado em Viçosa-MG. Revista Brasileira de Fruticultura, Jaboticabal - SP, v.34, n.2, p.619-623, 2012.

ATAÍDE, E.M.; OLIVEIRA, J.C.; RUGGIERO, C. Florescimento e frutificação do maracujazeiro silvestre Passiflora setacea D. C. cultivado em Jaboticabal, SP. Revista Brasileira de Fruticultura, v.34, n.2, p.377-381, 2012.

AZZOLINI, M.; JACOMINO, A.P.; BRON, I.U. Índices para avaliar qualidade pós-colheita de goiabas em diferentes estádios de maturação.

Pesquisa Agropecuária Brasileira, Brasília, v.39, n.2, p.139-145, 2004.

BERILLI, S.D.S.; OLIVEIRA, J.D.; MARINHO, A.B.; LYRA, G.B. et al. Avaliação da taxa de crescimento de frutos de mamão (Carica papaya L.) em função das épocas do ano e graus-dias acumulados. Revista Brasileira de Fruticultura, v.29, n.1, p.11-14, 2007.

CERQUEIRA-SILVA, C.; CONCEIÇÃO, L.; SOUZA, A. et al. A history of passion fruit woodiness disease with emphasis on the current situation in Brazil and prospects for Brazilian passion fruit cultivation. European

Journal of Plant Pathology, v.139, n.2, p.255-264, 2014. 
CHITARRA, M.I.F.; CHITARRA, A.B. Qualidade pós-colheita. Pós-colheita de frutas e hortaliças: fisiologia e manuseio, 2005. v.2, p.541-753.

COBRA, S.S.O.; SILVA, C.A.; KRAUSE, W. et al. Características florais e polinizadores na qualidade de frutos de cultivares de maracujazeiro-azedo. Pesquisa Agropecuária Brasileira, v.50, n.1, p.54-62, 2015.

CÓRDOVA, K.R.V.; BEZERRA, J.R.M.V.; KASKANTZIS NETO, G. et al. Determinação das Características Físico-Químicas e Sensoriais de Sucos Concentrados de Maracujá. RECEN-

Revista Ciências Exatas e

Naturais, v.10, n.2, p.191-199, 2010.

DIAS, T.J.; CAVALCANTE, L.F.; NUNES, J.C. et al. Qualidade física e produção do maracujá amarelo em solo com biofertilizante irrigado com águas salinas. Semina: Ciências Agrárias, v.33, p.2905-2918, 2012.

DURIGAN, J.F.; SIGRIST, J.M.M.; ALVES, R.E. et al. Qualidade e tecnologia pós-colheita do maracujá. In: LIMA, A. de A.; CUNHA, M.A.P. da (Ed.). Maracujá: produção e qualidade na passicultura. Cruz das Almas: Embrapa Mandioca e Fruticultura, 2004. p.281-303.

GIOVANAZ, A.; FACHINELLO, J. C; GOULART, C. et al. Produção e qualidade de pêssegos, cv. Jubileu, com uso de fitorreguladores. Revista Ceres, Viçosa, v.61, n.4, p.552-557, 2014.

GRECO, S.M.L.; PEIXOTO, J.R.; FERREI RA, L.M. Avaliação física, físico-química e estimativas de parâmetros genéticos de 32 genótipos de maracujazeiro-azedo cultivados no Distrito Federal. Bioscience Journal, v.30, p.360-370, 2014.

IBGE - Instituto Brasileiro de Geografia e Estatística. Produção Agrícola

Municipal. 2016. In: https://sidra.ibge.gov.br/ pesquisa/pam/tabelas (Acessado em 04 maio de 2017).

FEDERAÇÃO DAAGRICULTURA DO ESTADO DO PARANÁ - FAEP. Classificação do maracujá-amarelo. 2015. In: http:// www.faep.com.br/comissoes/frutas/cartilhas/frutas/ maracuja.htm. (Acessado em 25 março. 2018).
FREIRE, J.S.; CALVACANTE, L.; REBEQUI, A.M. et al. Physical characteristics of fruit of yellow passion fruit produced in soil with bio-fertilizer, mulching and saline water. Idesia, África, v.32, n.1, p.71-78, 2014.

SALAZAR, A.H.; SILVA, D.F.P.; SEDIYAMA, C.S. et al. Caracterização física e química de frutos de maracujazeiro-amarelo enxertado em espécies silvestres do gênero Passiflora cultivado em ambiente protegido. Revista Brasileira de Fruticultura, Jaboticabal, v. 37, n. 3, p. 635$643,2015$.

KRAUSE, W.; NEVES, L.G.; VIANA, A.P. et al. Produtividade e qualidade de frutos de cultivares de maracujazeiro-amarelo com ou sem polinização artificial. Pesquisa Agropecuária

Brasileira, v.47, n.12, p.1737-1742, 2012.

MACIEL, S.C.; NAKANO, D.H.; REZENDE, J.A.M. et al. Screening of Passiflora species for reaction to Cowpea aphid-borne mosaic virus reveals an immune wild species. Scientia Agricola, v.66, p.414-418, 2009.

MCATEE, P., KARIM, S., SCHAFFER, R. J.; DAVID, K. A dynamic interplay between phytohormones is required for fruit development, maturation, and ripening. Frontiers in Plant Science, v.4, p.79, 2013.

MCGUIRE, R.G. Reporting of objective color measurements. HortScience, Virgínia, v.27, p.1254-1260, 1992.

MEDEIROS, S.A.F.; PIRES, M.C.; YAMANISHI, O.K. et al. Desempenho agronômico de progênies de maracujazeiro-roxo e maracujazeiro-azedo no Distrito Federal. Revista Brasileira de Fruticultura, v.31, p.778-783, 2009.

MORAIS, K.D.B.; XAVIER, B.S.; SILVA, D.F.P. et al. Avaliação física e química de frutos de cultivares de pessegueiro. Revista

Engenharia na Agricultura, Viçosa, v.25, p.157-163, 2017.

NASCIMENTO, T.B.; RAMOS, J.D.; MENEZES, J.B. Características físicas do maracujá-amarelo produzido em diferentes épocas. Pesquisa Agropecuária Brasileira, Brasília, v.34, n.12, p.2353-2358, 1999. 
RINALDI, M.M.; COSTA, A.M.; FALEIRO, F.G. et al. Conservação pós-colheita de frutos de Passiflora setacea DC. submetidos a diferentes sanitizantes e temperaturas de armazenamento.

Brazilian journal of Food Technology, v.20, p.1-12, 2017.

ROTILI, M.C.C.; VORPAGEL, J.A.; BRAGA, G.C. et al. Atividade antioxidante, composição química e conservação de maracujá-amarelo embalado com filme de PVC. Revista

Brasileira de Fruticultura, v.35, n.4, p.942-952, 2013.

SANTOS, J.A.; NASSER, F.A.C.M.; NASSER, M.D. Qualidade dos frutos de goiabeiras submetidas à poda e aplicação de nitrato de potássio. Cultura Agronômica, v.24, n.4, p.271-280, 2015.

SCHMILDT, E.R.; ALEXANDRE, R.S.; SIQUEIRA, A.L. et al. O Dimensionamento amostral para analisar caracteres físicos e químicos de frutos de maracujá fedorento. Revista Ceres, v.64, n.2, 2017.
SILVA, D.F.P.; MATIAS, R.G.P.; SILVA, J.O.C.E. et al. Characterization of white-fleshed peach cultivars grown in the Zona da Mata area of Minas Gerais State, Brazil. Comunicata Scientiae, Bom Jesus, v.7, p.149-153, 2016.

SILVA FILHO, E.D.; FIGUEIRÊDO, R.M.F.; QUEIROZ, A.J. M.; BRASILEIRO, J. L. O. Variáveis físicas, químicas e reológicas da polpa integral da manga cv. Haden. Engenharia na Agricultura, v.23, p.397-405, 2015.

STATISTICAL ANALYSIS SYSTEM. SAS Institute Cary, N.C. EEUU. Version 9.0. 2002.

TREVISAN, R.; PIANA, C.F.B.; TREPTOW, R.O. et al. Perfil e preferências do consumidor de pêssego (Prunus persica) em diferentes regiões produtoras no Rio Grande do Sul. Revista Brasileira de Fruticultura, Jaboticabal, v.32, n.1, p.90-100, 2010.

VIANNA-SILVA, T.; LIMA, R.V.; AZEVEDO, I.G. et al. Determinação da maturidade fisiológica de frutos de maracujazeiro amarelo colhidos na região norte do estado do Rio de Janeiro, Brasil. Revista Brasileira de

Fruticultura, v.32, n.1, p.57-66, 2010.

Recebido para publicação em 1/4/2018 e aprovado em 27/6/2018. 